\title{
Challenges and Coping: Perspectives of Syrian and Iraqi Refugee Youth in Germany
}

\author{
Lina Alhaddad 1,2 (D), Robin Goodwin 3 , \\ and Patricia Kanngiesser ${ }^{1,4}$ (iD
}

\begin{abstract}
Refugee youth constitute around a third of the refugee population in Germany. We studied the experiences of newly arrived Syrian and Iraqi refugee youth, aged 14 to 18 years $(N=20)$, in Germany. We utilized semistructured interviews and thematic analysis to investigate (a) the main challenges faced by youth and (b) their main coping resources to deal with these challenges. We grouped challenges into three levels: the individual level, the immediate social level, and the broader societal level. The most frequently mentioned challenges in our sample related to psychological wellbeing, school, friendship, accommodation, and discrimination. Youth reported relying on social support (friends, family, social services) and on themselves (through avoidance, persistence, activity seeking, active engagement) to cope with their challenges. Our findings provide insights into refugee youth's experiences in Germany, encompassing the acculturative, developmental, and generational aspects of their lives and demonstrating their coping and resilience. We discuss our results in relation to the literature on refugee youth in high income countries.
\end{abstract}

\footnotetext{
'Freie Universität Berlin, Berlin, Germany

2Martin Luther University Halle-Wittenberg, Germany

${ }^{3}$ Warwick University, Coventry, UK

${ }^{4}$ University of Plymouth, UK
}

\section{Corresponding Author:}

Lina Alhaddad, Institute for Pedagogy, Educational Psychology, Martin-Luther-Universität Halle-Wittenberg, Franckeplatz I, Haus 5, EG R. 17, 06099 Halle, Germany.

Email: I.alhaddad@fu-berlin.de 


\section{Keywords}

refugee youth, challenges, coping, Germany, Middle East

In the past decade, political turmoil and armed conflicts in the Eastern Mediterranean region have resulted in the largest refugee population in the world (UNHCR, 2018). As a consequence, many refugees have embarked upon the perilous journey to Europe (Ostrand, 2015; Sirin \& Rogers-Sirin, 2015). In the summer of 2015, Germany temporarily suspended the Dublin Regulation $^{1}$ and subsequently witnessed the highest number of asylum applicants on record (Crul et al., 2017). According to recent figures, Germany currently hosts more than one million refugees and ranks fifth in the list of countries hosting refugees worldwide (UNHCR, 2020). Reports published by the German Federal Office for Migration and Refugees show that, in 2017 and $2018,{ }^{2} 35 \%$ of asylum seekers were children and adolescents and a third of the refugee population in Germany came from Syria and Iraq (Bundesamt für Migration und Flüchtlinge, 2017, 2018). Refugee adolescents do not only have to navigate the challenges of adapting to their host country, they simultaneously face developmental tasks such as negotiating relationships with parents, friends, and forming their sense of self (Brough et al., 2003; Jugert \& Titzmann, 2020).

\section{Challenges for Refugee Youth}

The challenges refugee youth face in their new country are often interrelated and nested in different contexts (AMSSA, 2016; APA Presidential Task Force on Immigration, 2012). Bronfenbrenner's ecological perspective provides a guiding framework to systemize these different contexts of the refugee youth experience and the main challenges they face in their new countries (Bronfenbrenner, 1977; Lustig, 2010; Suárez-Orozco et al., 2018). The current study focuses on three levels of the ecological systems model, namely the individual level (e.g., mental health, acculturative stress), different domains of the microsystem (e.g., family, school, living conditions) and how they interact, and the macrosystem (e.g., societal factors). The exosystem and chronosystem were not investigated.

Research has established that exposure to war and adversities negatively impacts the psychological well-being and mental health of refugees. Reviews show that $19 \%$ to $54 \%$ of refugee youth and children living in Europe and North America exhibit PTSD (Post Traumatic Stress Disorder) and around 30\% depression (Abou-Saleh \& Christodoulou, 2016; Bronstein \& Montgomery, 2011; Fazel et al., 2012; Hassan et al., 2016; Henley \& 
Robinson, 2011; Kirmayer et al., 2011; Lustig et al., 2004; Tam et al., 2017). In Germany, a recent study with asylum seeking minors from Afghanistan, Syria, and Eritrea found that $36.7 \%$ of accompanied minors scored above the clinical cut-off for Post-Traumatic Stress Symptoms (PTSS), 30\% for depression, and $23.3 \%$ for anxiety, with even higher prevalence for unaccompanied minors $(64.7 \%$ for PTSS, $42.6 \%$ for depression, $38.2 \%$ for anxiety; Müller, Büter, et al., 2019). These figures are considerably higher than those for German youth in general, ${ }^{3}$ of which $17.9 \%$ manifest depressive symptoms and less than 2\% PTSD (Essau et al., 2000a, 2000b). A longitudinal analysis of mental health in young Middle Eastern refugees in Denmark showed that symptoms decreased over time, suggesting a role of length of stay in the new country (Montgomery, 2010).

In addition to potential challenges to their mental health, refugees often experience losing all that is familiar as they face new languages, values, and cultures that are distant from their own, when they arrive in their new country (d'Abreu et al., 2019; Kirmayer et al., 2011; Lustig et al., 2004; Papadopoulos, 2001). Intercultural contact often results in a process of cultural and psychological change, called "acculturation," and the outcomes of said process can determine newcomer youth's adaptation to their new life (Berry et al., 2006). In the context of migrant youth, the age at which an adolescent moves to a new country has been shown to determine whether they undergo an acculturative process (integrating one's home culture and the new culture) or an enculturating process (learning the norms of one's society; Titzmann \& Lee, 2018). There are no studies, to our knowledge, on acculturation orientation in refugee adolescents, but a recent study on adult Syrian refugees in Germany showed that an affiliation with the culture of the new country promoted overall mental health (Green et al., 2019).

In the literature on the experiences of newcomer refugee youth, three domains of the microsystem are relevant to their wellbeing in their new countries, namely (1) education, (2) family, and (3) living conditions. Education was highlighted as a top priority for refugee youth in studies conducted in Australia and Germany (Gifford et al., 2009; Gruttner et al., 2018 ). Yet, only $23 \%$ of refugee children around the world are enrolled in secondary school, compared to $84 \%$ of the world's children (UNHCR, 2017). Even when refugee youth attend school, they face several difficulties. For example, a study in Canada found that, due to insufficient language skills, newcomer refugee youth were often placed in classes that failed to match with their academic level in their home country (Shakya et al., 2012). In a review on migrant youth in Germany, Frankenberg et al. (2013) noted that migrants of all age groups succeeded less often in the German school system and were at least four times more likely to repeat a 
school year. Additionally, migrant youth were often streamed into schools that provided fewer years of schooling ("Hauptschule," "Realschule"), which negatively impacted future academic opportunities such as attending university (Frankenberg et al., 2013).

Family is an important aspect of the experience of refugee youth. Life in a new country can influence family roles and values (e.g., greater emphasis on autonomy, independence, freedom) which often have the potential to positively or negatively impact adolescents' wellbeing (Anderson, 2001; Brough et al., 2003; Greenfield et al., 2003; Hassan et al., 2016). The family can be both a protective and a risk factor for refugee youth (Alami, 2020; McMichael et al., 2011). While communication, family cohesion and good parental mental health are considered protective factors (Fazel et al., 2012; Lustig, 2010), lack of trust between parents and their children, conflict in the family (between parents and their children and between parents), and domestic violence are considered risk factors (Hassan et al., 2016; McMichael et al., 2011). For unaccompanied refugee youth, separation from their family as well as difficult procedures of family reunification often result in psychological distress (Muller, Brewer, et al., 2019). Refugee youth also endure other disruptions of their social networks upon leaving their home country such as separation from friends and acquaintances (Kirmayer et al., 2011).

Third, living conditions in a new country, such as uncertainty regarding their legal status and socio-economic strains, shape young refugees' experience and adaptation to their new life (Alami, 2020; Anderson, 2001; Fazel et al., 2012). Additionally, housing represents a multifarious challenge for refugee youth. A longer stay in refugee accommodation centers, frequent relocation between accommodation centers, the inadequate conditions of refugee accommodation centers, and the difficulty of finding a private accommodation impact young refugees' psychological wellbeing (Anderson, 2001; Braun-Lewensohn \& Al-Sayed, 2018; Nielsen et al., 2008).

On the broader societal level, factors such as political climate and public attitude can affect adolescents' overall sense of wellbeing (Frankenberg et al., 2013). In a recent large-scale panel study on discrimination in Germany, more than a third of participants, aged 14 and above, reported encountering discrimination based on factors such as their ethnic origin, gender, disability, religion or world view, age, or sexual identity (Beigang et al., 2016). Exposure to discrimination, both experienced and perceived, has been identified as a risk factor to the well-being of refugee youth in studies in Europe, North America, and Australia (Brough et al., 2003; Ellis 
et al., 2008, 2010; Fazel et al., 2012; Hassan et al., 2016; Montgomery \& Foldspang, 2008; Patel et al., 2014; Shakya et al., 2010). A study in Denmark found that middle Eastern refugee youth reported on average 1.8 experiences of discrimination since having arrived in the country up to 3 years before (Montgomery \& Foldspang, 2008).

\section{Developmental Tasks in the Context of Refugee Youth}

In addition to acculturative challenges, refugee youth have to navigate adolescence-specific developmental tasks (Jugert \& Titzmann, 2020). In adolescence the relationship with parents shifts as adolescents spend less time with parents, involve them less frequently in decisions and seek meaningful connections with their peers (Petersen, 1988). When discussing refugee adolescents and their relationship with their parents, it is imperative to recognize that autonomy (and its counterpart, relatedness) are valued differently across cultures (Greenfield et al., 2003; Kagitcibasi, 2005). In that regard, differences between parents' values and expectations and the values of the new country can cause tension for newcomer youth, and affect their relationship with their parents (Motti-Stefanidi \& Masten, 2017). For example, parents may expect adolescents to choose friends that align with the values of their heritage culture; on the other hand, peers may expect newcomer adolescents to conform to the values of their culture. Ultimately, the way in which adolescents resolve these contrasting expectations informs their choice of close friends (Baolian Qin, 2009). Importantly, previous research suggests that refugee adolescents' resistance to conform to cultural expectations of their new country might increase the risk of being bullied by their peers, particularly in the school context (Schachner et al., 2018).

\section{Coping by Refugee Youth}

Despite the multitude of challenges faced by refugee youth, they often show remarkable resilience and coping (Henley \& Robinson, 2011; Lustig et al., 2004; Patel et al., 2017; Ward, 2001). Coping can be defined as "constantly changing cognitive and behavioral efforts to manage specific external and/or internal demands that are appraised as taxing or exceeding the resources of the person" (Lazarus \& Folkman, 1984, p. 141). These demands can be met with two types of responses: (1) problem focused coping, which refers to behavior aimed at changing features of the stressful environment, and (2) emotion based coping, which refers to changing one's perception and appraisal of stressful events (Lazarus \& Folkman, 1984; Ward, 2001). 
Research has found that actively engaging with the challenges at hand and exerting effort to change stressful circumstances has a positive impact on adolescents' long term adjustment (Ebata \& Moos, 1991). However, adolescents' general mental health can influence their coping response: the same study found that adolescents with depressive symptoms did not rely on active engagement and instead demonstrated more avoidance (Ebata \& Moos, 1991). Moreover, the extent to which refugee adolescents are able to change aspects of their environment impacts their coping. For example, adolescents have varied levels of agency over stressors such as education and discrimination, which in turn leads them to adopt different coping strategies to deal with these stressors (Khawaja et al., 2008; Ward, 2001).

Only few studies have focused on coping amongst refugee youth. A qualitative study with newcomer refugee youth in Australia revealed that adolescents relied on social support from family, friends, and engaged in individual and community activities (Brough et al., 2003). Similar results were found for Somali refugee youth in the US (Goodman, 2004). A recent study by Muller, Brewer, et al. (2019) showed that newcomer refugee youth of multiple ethnic backgrounds in the US used both emotion focused coping and problem focused coping. Interestingly, the study also revealed that coping was stressor and situation specific, and that adolescents adapted their coping response to the situation at hand: When youth felt no agency to resolve the stressor or perceived that it could be harmful to do so, they were more likely to rely on emotion focused coping (Muller, Brewer, et al., 2019).

\section{The Current Study}

Previous research has highlighted the importance of studying refugees' experiences in their new country, as those experiences can impact their well-being on the long-term (Montgomery, 2010). The German context is unique due to the high numbers of refugees from Syria and Iraq that have arrived since 2015. Yet, studies with refugee youth in Germany are still scarce and have mostly focused on mental health (Müller, Büter, et al., 2019; Müller, Gossmann, et al., 2019) and education (Crul et al., 2017; Frankenberg et al., 2013; Gruttner et al., 2018). To our knowledge, few studies have investigated refugee youth's own perspective on their new lives and challenges in Germany. Moreover, to overcome a purely deficits focused perspective on refugee youth (Baker \& McEnery, 2005; Keddie, 2012; Ryu \& Tuvilla, 2018), our study also examined coping resources of refugee youth in Germany. This allowed us to address a significant gap in the current literature on coping by 
refugee youth in Germany and contributes to the literature on positive youth development (Chung et al., 2021). We conducted a qualitative interview study with Syrian and Iraqi refugee youth in Germany to address the following two research questions:

(1) What are the main challenges faced by refugee youth from Syria and Iraq?

(2) How do refugee youth cope with these challenges, and who supports them?

\section{Method}

\section{Participants}

Twenty participants ( 7 female, 13 male) between the ages of 14 and 18 years $(M=16.00, S D=1.72)$ took part in the study. Fourteen participants $(70 \%$; five female) were Syrian, and six were Iraqi (30\%; two female). For further socio-demographic details, see Table 1. Participants had arrived in Germany on average 20 months (SD 8.8 months, range $=1-33$ months) before the interview took place. Sixteen participants had journeyed through the Balkan route to Germany and four arrived in Germany via plane with a family reunion visa.

We recruited 14 participants from Berlin and six from Potsdam. At the time of the study, Berlin had approximately 3.7 million inhabitants and nearly one-third $(27.7 \%)$ of the population had a migration background (Amt für Statistik Berlin-Brandenburg, 2019; OECD, 2018). Potsdam, a city that borders Berlin on the west, had approximately 184,000 inhabitants, $11.9 \%$ of whom had a migration background (Amt für Statistik BerlinBrandenburg, 2018; Bereich Statistik und Wahlen der Landeshauptstadt Potsdam, 2019).

We interviewed five additional participants but did not include them in the final data set because they differed substantially from the rest of the sample: Two were unaccompanied adolescents, one adolescent had a hearing and visual disability, one adolescent was married and had children, and one adolescent had insufficient Arabic language skills.

The study was approved by the ethics committee of the Faculty of Education and Psychology at Freie Universität Berlin (approval no. 157_2/2017). Data collection started in November 2017 and ended in July 2018. As a thank you for their participation, participants received an $€ 8$ shopping voucher from an electronics store. 


\section{Recruitment}

We recruited adolescents using three different methods. First, we contacted accommodation centers in Berlin and received permission from two centers to recruit adolescents ( $n=11$, three female). After gaining the approval of the management of these two refugee accommodation centers in Berlin, we contacted all Arabic speaking families living there with children aged 14 to 18 years and informed them about the study. The first author explained that the research aimed to understand the experience of young Arabic speaking refugee youth in Germany. Contacted parents raised no concerns regarding the study and every contacted family agreed to the participation of their teenage children. After parents had given their informed consent for their teenage children to participate, we contacted adolescents and invited them to take part in the study. All adolescents gave informed consent before participating. All participants were interviewed in a quiet room in their accommodation center. Importantly, we informed both accommodation centers and families that data collection was conducted solely for research purposes and would neither affect the funding for the accommodation center nor influence the asylum application process of the families. We faced challenges while recruiting participants in accommodation centers as most of the contacted organizations never replied to us, refused to take part, or operated on yearly contracts and occasionally closed. Hence, we had to rely on two additional recruitment strategies to complete our sample.

Second, we contacted local initiatives that provided support to or organized activities for refugee adolescents and recruited participants in an activity center $(n=6$, three female). This center offered free-time activities for adolescent refugees in Potsdam and allowed us to contact adolescents aged 14 years and older. We interviewed them in the accommodation center where the free-time activities took place. Two participants lived in accommodation centers in Potsdam (one participant was living at the center where the study took place) and four lived in private apartments in Potsdam. Adolescents gave informed consent before taking part in the study. We did not obtain parental consent for this group, as we did not contact them through their parents (note that adolescents aged 14 years and older do not require parental consent to participate in non-invasive, psychological studies in Germany).

Third, we used snowballing sampling ( $n=3$, one female). We recruited these participants in Berlin through their friends who had already taken part in the study and recommended the study to them. All of them lived in private apartments and agreed to complete the interview in the nearby accommodation center where their friends lived. Adolescents gave informed consent before taking part in the study; no parental consent was obtained. 
Table I. Socio-Demographic Details of Participants.

\begin{tabular}{lr}
\hline & $\mathrm{N}(\%)$ \\
\hline Country of origin & \\
Syria & $14(70)$ \\
Iraq & $6(30)$ \\
Ethnicity & \\
Arab & $16(80)$ \\
Kurdish & $2(10)$ \\
Izidi & $2(10)$ \\
Religion & \\
Islam & $15(75)$ \\
Izidi & $2(10)$ \\
None & $3(15)$ \\
School & \\
Regular classes & $13(65)$ \\
Welcome classes & $7(35)$ \\
Legal status & \\
Asylum status & $10(50)$ \\
Subsidiary protection & $4(20)$ \\
Rejection & $2(10)$ \\
Family reunion visa & $4(20)$ \\
Accommodation type & \\
Refugee center & $13(65)$ \\
Private & $7(35)$ \\
\hline
\end{tabular}

\section{Procedure}

The first author, a Syrian counseling psychologist and a native Arabic speaker, conducted all interviews in Arabic. The first author piloted the interview procedure and script with adults and one refugee adolescent. Pilot interviews were videotaped, and the first author received feedback from the third author throughout the pilot phase.

The main interviews took place in a quiet room and all participants were interviewed individually. When meeting participants, the interviewer engaged them first in small talk to establish rapport and to ensure they felt comfortable. Only then would the interview begin: participants received an explanation of the goal of the study and a description of the interview procedure. Next, the interviewer guided them through the informed consent form. For those who had difficulty reading in Arabic, she read the consent form out aloud. Participants also received a brief explanation of the field of 
psychology ${ }^{4}$ and what a research study entailed. All contacted adolescents agreed to taking part in the study, signed a consent form and, in addition, the interviewer asked whether they agreed to be audio recorded. At that point, the interviewer switched the voice-recorder on.

The interview began with a series of socio-demographic questions asking participants about their age, gender, religious and ethnic affiliations, their journey to Germany, their school attendance in Germany, and their legal status in Germany (see Supplemental Material for the full socio-demographic survey). The interviewer collected this information verbally for all participants and live-coded their responses.

The first question of the interview probed participants' daily routines in Germany, then the interviewer proceeded to asking participants about the biggest challenges they had faced since arriving to Germany, how they had dealt with each of these challenges, and who had helped them. After that she followed up with scripted questions probing for challenges in five domains of participants' lives in Germany (studying and school, accommodation, financial situation, health, their emotions since arriving in Germany), unless participants had already mentioned challenges in these domains in response to the previous question (biggest challenge). For each domain, the interviewer also inquired how they had dealt with each challenge and who helped them. Table 2 presents English translation of the complete list of interview questions (see Supplemental Material for the interview script in Arabic).

During the interviews, the interviewer utilized her active listening skills to minimize influence on participants' responses, and to avoid reactions that might have condoned or condemned participants' answers. Interviews varied in the length, and while some participants responded in great detail, others gave brief answers. On average, the recorded section of the interview lasted 22 minutes, with a range of 16 to 39 minutes. The entire session (including warm-up, introduction to study and the recorded interview section) lasted approximately 30 minutes to an hour.

\section{Data Coding}

An Egyptian native speaker of Arabic (not the first author) transcribed all interviews using F4transcript (Dresing et al., 2015). The first author then checked and proofread these transcripts. After that, the person who had transcribed the interviews translated them to English. To ensure accuracy, the first author checked the translated transcripts and compared them with the Arabic original. Discrepancies were corrected by the first author.

We analyzed the interviews inductively using thematic content analysis (Braun \& Clarke, 2006; Green et al., 2007; Pope et al., 2000). Specifically, 
Table 2. English Translation of the Complete List of Interview Questions.

\begin{tabular}{|c|c|}
\hline Order & Question text \\
\hline I & Please describe your daily routine. \\
\hline 2 & What are some challenges you face in your daily life? \\
\hline 3 & $\begin{array}{l}\text { What are the three most challenging situations you have } \\
\text { faced since coming to Germany? }\end{array}$ \\
\hline \multirow[t]{3}{*}{3.1} & $\begin{array}{l}\text { How has your experience with studying and school been } \\
\text { since you came to Germany? }\end{array}$ \\
\hline & Do you have someone to study with/ help you with studying? \\
\hline & $\begin{array}{l}\text { Do you understand the German educational system (e.g., } \\
\text { how to plan your studies) }\end{array}$ \\
\hline 3.2 & $\begin{array}{l}\text { How has your accommodation situation been since you came } \\
\text { to Germany? }\end{array}$ \\
\hline 3.3 & $\begin{array}{l}\text { How has your financial situation/money been since you came } \\
\text { to Germany? }\end{array}$ \\
\hline 3.4 & How has your health been since you came to Germany? ${ }^{\text {b }}$ \\
\hline 3.5 & $\begin{array}{l}\text { How have your emotions and feelings been since you came } \\
\text { to Germany? }\end{array}$ \\
\hline 4 & What is your impression of Germany? \\
\hline 5 & What is your impression of Germans? \\
\hline 6 & What are your wishes for the future \\
\hline 7 & What are your plans for the future? \\
\hline
\end{tabular}

${ }^{a}$ This question is followed up by questions 3.1 to 3.5 .

bFor each challenge mentioned, the interviewer asked: How did you face this problem? Who helped you?

the first author thoroughly read all the transcripts and then developed line by line in vivo codes (Kuckartz, 2014) for a selection of eight representative interviews, taking into consideration gender, time since arrival to Germany, and accommodation type. In this step, she reduced each sentence of the transcript to keywords. The first and last author then grouped these keywords into comprehensive main categories and developed a coding guide (for more on this see Supplemental Material). Next, the first author coded all 20 transcripts in F4Analyse (Dresing et al., 2015). To ensure that the main categories were coded reliably, we trained a second coder (none of the authors). She first coded three interviews that were not part of the main data set, received feedback and then independently scored all 20 transcripts. Next, we compared all statements coded by the first and second coder. If both coders assigned the same section of the transcript to the same category, we considered this a match. If only one coder scored a section, we considered this a mismatch. There were $73 \%$ matches (361 matches, 131 mismatches) between the first 


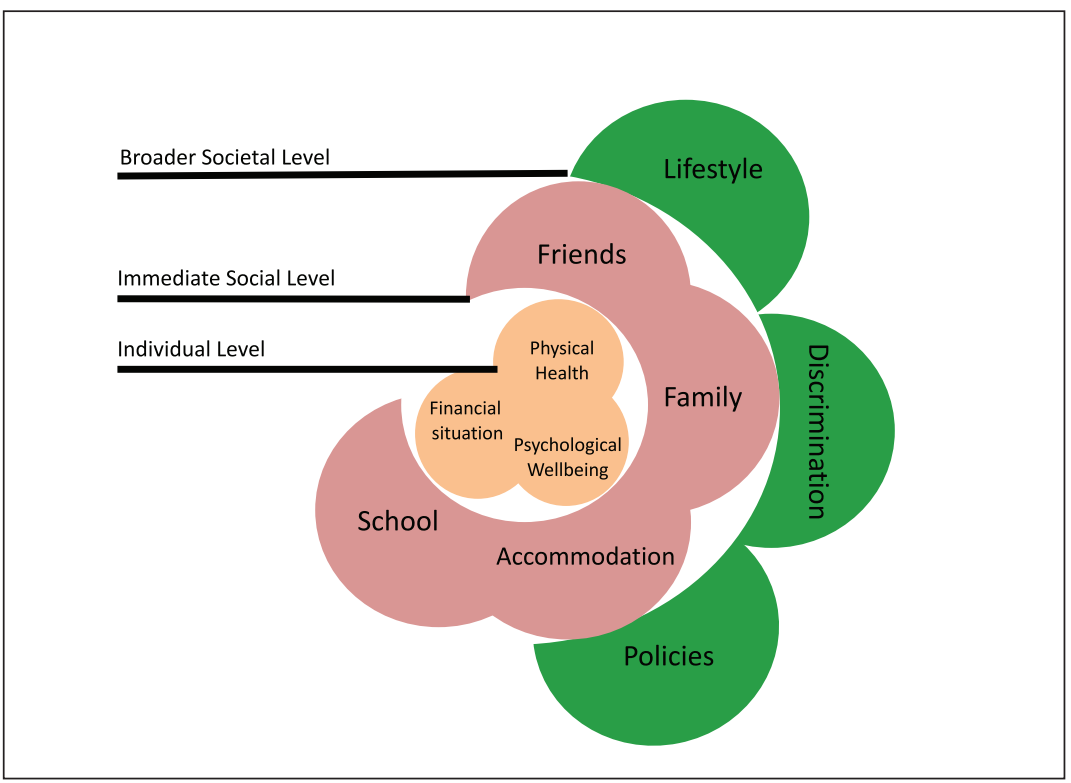

Figure I. Main challenges reported by refugee adolescents in our study.

author and the second coder. Next, the two coders discussed all mismatches to arrive at a consensus coding ( $63 \%$ of the time, the decision sided with the first author's coding). Using the statements from the consensus coding, the first and last author identified sub-themes within the main categories and categorized the statements accordingly.

\section{Results}

We organized participants' statements into two main themes to answer our research questions about (1) the main challenges faced by refugee youth from Syria and Iraq, and (2) refugee youth's coping with these challenges. We used the ecological framework of Bronfenbrenner and Morris (1998) as a guide to systematize adolescents' challenges and investigated youth's coping inductively. The result section is structured to address these questions separately.

\section{What Challenges Do Refugee Youth in Germany Face?}

We grouped participants' challenges into three main spheres (Bronfenbrenner \& Morris, 1998): the individual, its immediate social level, and broader societal level (see Figure 1 for an illustration). At the individual level, participants 
reported challenges relating to their psychological wellbeing, physical health, and financial situation. At the immediate social level, participants faced challenges with family, friends, school, and accommodation. The broader societal level included experiences of discrimination, and challenges with a new lifestyle and, policies and bureaucracy in Germany. Table 3 illustrates the prevalence of these challenges amongst participants.

\section{Challenges at the individual level}

Psychological well-being. When asked about their emotional and psychological state since arriving in Germany, 16 adolescents reported negative emotions. Most participants used generic descriptions such as "upset, tired, difficult, not good, bad" and only one participant, who was in therapy at the time of the interview, used the term "depressed."

Starting over in a new country and abandoning previous hopes and dreams negatively affected four participants' well-being as illustrated by the following statement:

I want to have a job, a car and a family. These were my wishes when I was in Iraq, I was there for 15 or 16 years and now, I am here. I put those wishes on the side when I came here, it's like starting over, like just being born from the mother's womb and having the first day in life. Everything that we did is now gone and I have to start over which is difficult and I need time to figure things out (boy, 18).

The majority of participants, who reported negative emotions, did so in relation to experiences of discrimination and challenges regarding family, education, and friends. We clustered these challenges in separate categories, which we will further discuss in the following sections.

Physical health. In total, eight participants reported health issues they experienced in Germany. One boy (16) mentioned being sick upon arriving to Germany "because of the road, weather change" and the fact that "the weather in Syria is very different from Germany." Another boy (15) reported an eye infection, which he attributed to the insanitary conditions of his accommodation center: "I caught a disease in the accommodation center with the mice, I don't know its name. My eyes turned red."

Financial situation. Apart from four participants, the majority of adolescents did not report any financial challenges. One boy (15) struggled financially as his family was split between Germany and his home country: "It is hard for my father because my father [sends money] to my mother and my sister [back home]." Another participant (boy, 17) reported that "my 


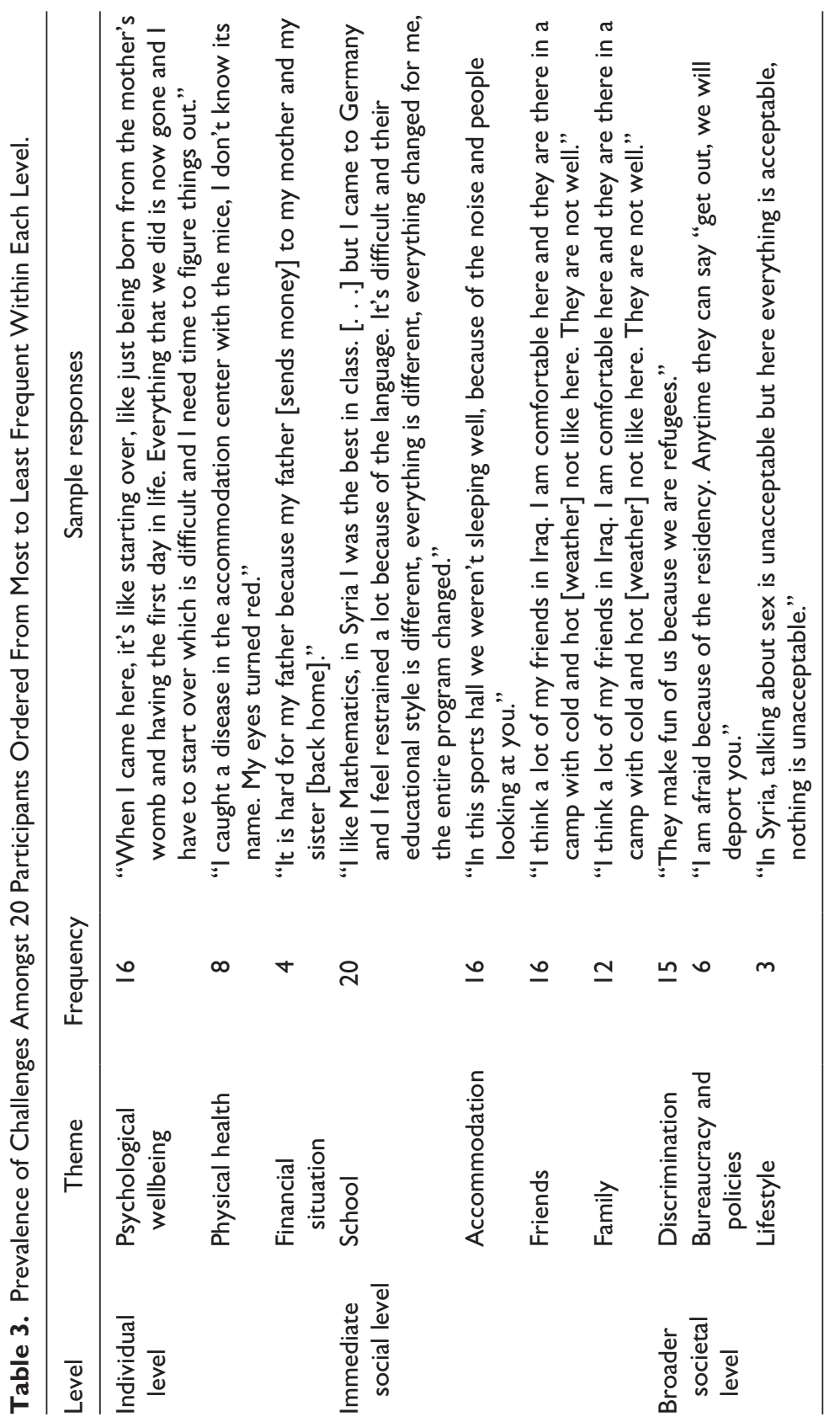


financial situation [. . .] was kind of bad but every day it is improving. It is [bad] because we had a problem in Greece where someone defrauded us, but now every day the financial situation is improving." An older participant (boy, 18) compared his financial situation to that of his peers, saying that "I see a friend [. . .], he bought a car and I say why can't I be the same thing. This is the nature of life and I just wish they give us the space to work more and get a job."

\section{Challenges at the immediate social level}

School. All participants attended school at the time of the interview and all of them reported some school-related difficulties. Fifteen participants perceived learning German, "speaking and grammar rules" and "coordinating all the rules together" (boy, 16) as a challenge. One participant stated:

I find a lot of difficulty in the language because it's not your language. It doesn't matter how much you learn it you will not know it. So, one always faces difficulties and now I am almost done, and I will go to grade nine by God's Will (girl, 15).

The struggle to learn German occasionally caused conflicts with teachers, as illustrated by the following boy (17):

I keep fighting with a teacher. I would read a whole text in German and pause over a word, and then she would say why you do not read fast. I tell her I was not born here in Germany, I am still new, and all of these words are new to me. She fights me, I fight her and so on.

Adolescents with insufficient German language skills usually first attended so-called "welcome classes" and once they had acquired sufficient language skills, they transferred to regular classes. This transition posed a challenge for the following girl (18):

During Welcome Classes we only had German, German grammar rules, new words, etc. When I joined my school, I saw that they were also teaching math, English, physics, chemistry and they knew the words specifically about the subject. For example, what is a square, what is a triangle. . .etc.

These difficulties were mirrored by the following boy (15), who reported struggling with a school subject he previously excelled in, and attributed this to insufficient language skills and differences in teaching styles:

[. . .] The most difficult subject, I like Mathematics, in Syria I was the best in class. [. . . ] but I came to Germany and I feel restrained a lot because of the 
language. It's difficult and their educational style is different, everything is different, everything changed for me, the entire program changed.

Some participants also worried that their proficiency in German would affect their career choices: "One must know the language very well before going to the 10th grade otherwise it will be very difficult. [ . . .] if I get good grades, I will go to the 10th grade but if not then I am obligated to do Ausbildung [professional apprenticeship]" (girl, 18). Another participant (boy, 18) felt pressured to start working instead of continuing his education:

They [the Job Centre, social welfare centre] don't care, they only want you to do an Ausbildung [professional apprenticeship]. I wanted to do an Abitur [German high school diploma], then go to university, but they don't care. They just want you to finish school quickly and then pay taxes.

Accommodation. When they first arrived in Germany, most refugees lived in accommodation centers and living conditions could vary between centers. Many participants reported dissatisfaction with their assigned accommodation, which was highlighted in statements such as "my home is small [. . .] studying is a problem for me at home" (boy, 18), "in this sports hall we weren't sleeping well, because of the noise and people looking at you" (girl, 15), "it was very dirty, even the food" (girl, 18). Some also reported that "there were problems in the hall and men fought, physically, and the police would come" (boy 15) and another shared that "there was a lot of thefts" (boy, 15).

Participants usually had to move at least once between different accommodation centers and one boy (15) described his experience graphically:

We move from centre to centre to centre, this is really bad. [. . .] They brought us to [name of the area]. [Name of the accommodation centre] was really big but really bad, it had a lot of refugees from all countries, really bad. We stayed there for about 2 months then after [name of the accommodation centre] we went to that other centre that had mice and we stayed there for a year. Everyone there was disgusted by it, including my family, they were really upset.

Many participants wished to move to private accommodation but found that process challenging for various reasons "because we didn't get a residence permit" (boy, 17) or "One can't move unless they work and I am young and I can't work, neither my sister nor my mother" (girl, 14).

Friends. Thirteen adolescents reported a multitude of challenges with friendships, as this girl (18) aptly summarized: 
The first problem is loneliness; the loneliness I felt at the beginning was very difficult. Sometimes I still feel it. In Syria, we always had our neighbours around us and one knows everyone in the neighbourhood. For example, one can hang out with one's friends even if they are not close but here one finds it very difficult.

The main sub-themes that emerged in this category included the challenge of making new friends in Germany and the challenge of sustaining already existing friendships back home or in Germany. Eight participants reported difficulties in making new friends and the following girl (18) reflected on the numerous reasons why this had been a challenge:

I can't blend in with the other students [at school]. I don't know if it is the age difference between us or if it is the language or if it is because we come from different countries or if it is something else. So, I don't blend in that much with the students in my school. Sometimes I think it's the age difference, but I feel I can't even blend in with the Arab students in my school.

Other participants mirrored these impressions, stating that "it is difficult to find someone to hang out with if you don't speak the language" (girl, 15) or that "there is an age difference between me and the others, they are 14 and I am 18, so I feel that my mind doesn't match their minds" (girl, 18). These statements highlight the dual effects of lack of language skills and of age differences due to interrupted schooling which created barriers to forming new friendships. One girl (15) attributed her struggle in making friends to the differences in friendship styles between her home country and Germany: "They [Germans] don't care for having one close friend. I want a friend to stay with and continue to be my friend."

Sustaining existing friendships, in Germany or back home, was a challenge for six participants. One boy (17) stated that "sometimes there are problems between my friends and I, or a problem between my best friend and me." Differences between living conditions in Germany and friends' living conditions back home burdened one girl (15) "I think a lot of my friends in Iraq. I am comfortable here and they are there in a camp with cold and hot [weather] not like here. They are not well" (Girl, 15). Lack of opportunities for face-to-face interactions with friends back home affected the following boy's friendships (18) “[. . . ] I don't like to stay in touch with people I don't see. [ . . .] I got busy and I didn't stay in contact with them. I came here and I am forced to start a new life here." Another challenge related to differences in political opinions, as the following girl (18) explained "I have some problems with my friends in Syria because of the current events." 
Family. Overall, 12 participants reported numerous challenges with regards to their family life, which we grouped into two sub-themes: "changes in family life" and "lack of independent decision making."

Changes in family life affected a girl (17), who lived with both of her parents in Germany. She described how resettlement had strained her parents' marriage: "My parents fight sometimes, and this upsets me. Being in diaspora it becomes compulsory to fight." Eight adolescents struggled with separation from parents and siblings. For example, one girl (15) "feels something is missing" without her mother and another boy (15) stated that "there is one thing I think about a lot, my mother, I want her to come here. It was very difficult for me to leave my mother and come here." For some this was associated with the feeling that "there is nothing I can do" to change the situation (girl, 15). Two participants reported losing members of their nuclear or extended family in the war. One of those participants (girl, 18) stated that "This was really difficult, and I haven't forgotten until now, but life goes on and one must."

Perceived lack of independent decision making was reported by four participants, who wished to have more say over everyday life decisions. One boy (15) stated "I wish I could transfer to [the school] where my friend is. [. . .] my family, I will not start this conversation with them. They will tell me no." In addition, some of these four adolescents stated that their parents had made the life changing decision to move to Germany, and that they "didn't want to come here in the first place but my mother made me" (girl, 18). This led one boy (15) to resent his father, saying that "I don't speak with my father because he separated us."

\section{Challenges at the broader societal level}

Discrimination. Fifteen participants mentioned that "racism sometimes is a difficult thing" (girl, 15). Participants described different experiences of discrimination including ones that were based on factors other than race such as language or religion. It should be noted that participants commonly used the term [عنصرية] unsuriya "racism" when referring to discrimination. In the everyday Arabic language, the term "discrimination," [تمييز], tamiyiz, literally translates to "differentiation." However, it does not convey a sense of differential treatment based on color of skin, religion, gender, sexual orientation, age, or socio-economic background. Participants described different types of discrimination, which we grouped into "obvious discrimination" and "ambiguous discrimination," respectively (Patel et al., 2014).

Obvious discrimination included experiences of being ridiculed, being called names, being asked to go back home, not to speak their mother tongue and being physically assaulted. Specifically, 12 participants described that 
they were called "Ausländer" (foreigner) or reported that "they say bad words to us" and "they make fun of us because we are refugees and came to them" (boy, 15). Others reported that they were told to" go back to your countries and leave Germany, go to your countries and don't stay here" (boy, 18) or that "you took everything from us" (boy, 18). For a girl (15), speaking her mother tongue in public provoked a discriminatory comment as a stranger told her "we are in Germany and we must speak German." One boy (14) shared a story of physical assault he experienced at school: "At the beginning when I was at school, I used to face some racism but not anymore. They used to call me refugee or foreigner. They assaulted me once [. . . ] physically."

We classified statements of four participants as ambiguous discrimination, in which participants reported that they felt discriminated against. However, we could not fully discern whether discriminatory intent was involved (i.e., no slurs or demeaning language were reported). For example, one girl (15) described her experiences with strangers and attributed their stares to her foreign appearance and language:

It maybe shows that I am Arab so if there is a Nazi or someone similar, they stare at you like you should go back to your country. I faced something not nice from someone in the tram if you speak Arabic with someone you get stared at and given the look like "what are you talking about."

The following girl (15) reported that others' reactions to conversations about religion made her feel uncomfortable, stating that "if we speak about our religion Islam, they are surprised, or they joke about it. They pay too much attention to the religion when at the end we are all the same" (girl, 15).

Bureaucracy and policies. Six adolescents reported challenges in this category, "Because first you don't know all the regulations and you don't understand the language" (boy, 18). Some reported difficulties with paperwork such as inconsistent spelling of Arabic names in Roman letters, ${ }^{5}$ as the following girl (15) stated:

My name is not like the name of my father. So, when I went to the Job Centre [social welfare office] the first thing, they would say is no. They would say I am not his daughter.

Other challenges with paperwork included renewal of documents, missing documents, or incomplete applications. In particular, applying for a residence permit and waiting for the outcome caused a lot of anxiety for participants as illustrated by the following statement: 
I am afraid because of the residency. Anytime they can say "get out, we will deport you" how can this happen, it can't happen. Residency is the most important thing. When the residency comes, one can feel that one settled a bit. My dad always talks on the phone about fellow refugees who cause problems. There are a lot of things happening and when these things happen, the situation worsens (boy, 15).

According to participants, obtaining a residence permit played a crucial role as it determined whether they would be able to move to private accommodation or get a job. For example, a boy (18) stated that "I just wish they give us the space to work more and get a job. But they don't allow us to get a job."

Difficulties were not only reported with regards to obtaining documents and permits, but also with regards to securing school places. One boy (18) reported that "when I first came it took them 7 months to place me in a school."

Adapting to German lifestyle. Three participants reported that they experienced challenges with "adjusting to living here with the Germans and in a European country" (girl, 15). One girl (18) elaborated on this topic, stating that "in Syria, talking about sex is unacceptable but here everything is acceptable, nothing is unacceptable" and explaining further:

[. . . ] many times I wish I can wear short dresses without thinking but when I do, I keep thinking about the fact that I am wearing a short dress. Even if it is hot and even though it is normal, I can't be comfortable.

\section{What Coping Responses Do Refugee Youth Show?}

During the interview, we asked participants how they had coped with each challenge they mentioned and who had helped them. We grouped participants' coping responses into two main categories: rely on social support and rely on self. We found that each participant mentioned these two main coping strategies during the interview. Across the sample both strategies were used to address the different challenges (with the exception of challenges relating to their financial situation), but to varying degrees (see Figure 2). In addition, four participants made faith-related statements that were grouped separately from the main categories.

Rely on social support. All participants expressed relying on social support and referenced different sources of support such as "my family helps me and I help them" (boy, 15), "only my friend [helps me]" (girl, 16), "I know a teacher in another school, she helps me" (boy, 17), or "I go to a social worker 


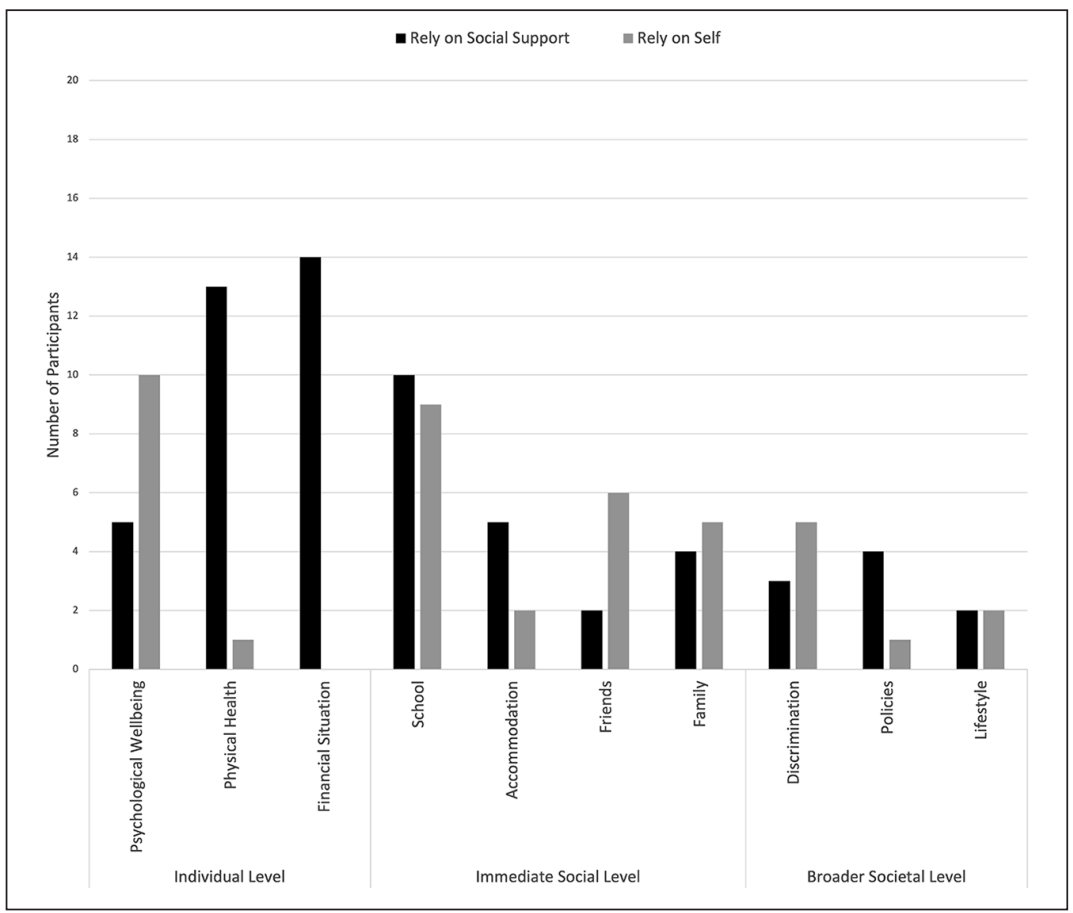

Figure 2. Different coping resources used per challenge across 20 participants.

here in the management [office in the accommodation centre] and ask her, I ask the security [guard ${ }^{6}$ ]" (boy, 15). Four participants reported relying on people from their community for support, this included "people in the accommodation centre" (boy,16), "the people who have been in Germany for a long time" (boy, 15; girl, 15), or the "Arab community" (boy, 18) more generally.

Rely on self. Seventeen participants also stated that they relied on themselves to mitigate the challenges of their new life in Germany. Some highlighted general self-reliance as in "I help myself" (boy, 15), while others elaborated more on the strategies they used. We grouped these more specific strategies into avoidance, persistence, seeking distraction, active engagement, and cognitive appraisal (ordered from most frequent to least frequent).

Avoidance of (potentially) problematic situations or places was mentioned by 11 participants. For example, one boy (15) reported that "the team I played with was all Germans and they hated us, so I stopped playing." Another participant, a girl (16), mentioned removing her Hijab (Islamic headdress that covers a woman's hair) as a reaction to experiencing discrimination: "I was 
veiled at the time and they don't like veiled women and when this [being called bad names] happened to me I took it off."

When faced with an obstacle, nine participants demonstrated persistence and exerted continuous and conscious effort to overcome it, as illustrated in the statement of this girl (15):

[. . .] I try to push myself at home so I can achieve what I want. I get home I translate everything that I didn't understand. If there is a lesson that I didn't understand I research it online and sometimes I use Google.

Seven adolescents reported engaging in activities to distract themselves from the challenges they faced. For example, one boy (18) stated "when I have a problem, I search for something to keep me busy until the time has passed," and a girl (18) reported that "I try to sleep or go out a bit. Sometimes I walk with music." Others distracted themselves with their mobile phones as illustrated by the following quote "I stay by myself and watch stuff on the phone" (boy, 15). The following girl (18) demonstrated resourcefulness in dealing with loneliness at school:

Well, I keep attending [school] but I don't do anything. Sometimes I try to speak to someone next to me or I try to forget about it, I try to breathe slowly, I try to draw if it's a drawing related subject or I try to listen to music if it's allowed because sometimes, they don't allow us.

Five adolescents reported active engagement with the challenges at hand and tried to resolve problematic situations. For example, a boy (15) addressed a problem at school and stated that "if we can resolve it, between me and the person, then we do so." A girl (15) reported standing up for herself when harassed in the tram for not speaking German: "I told her that it's not her business to tell us what we do since we are on the street not at school."

To cope with a challenge, three participants reported changing (or attempting to change) their mindset. The following girl (15) relied on optimism and hope of a better future, reporting that "I convince myself that what is yet to come is better, just like that I try to overcome my feelings." Another participant (boy, 15) exercised self-control when experiencing discrimination:

I was going to hit him but there are rules here and hitting is not allowed. I controlled myself and didn't hit him, and then it became normal.

Lastly, a girl (18) struggled with her new life in Germany and reflected on her experience as follows: 
I am still lost. But sometimes I tell myself I came here, and I have to adjust and sometimes I tell myself I have to keep my customs that I was raised with. Yet sometimes I see that here is right and there is wrong. Sometimes I see that there is right and here is wrong.

Rely on faith. In some cases, participants used the following terms Thank God "الحمد لله" These are very common expressions in the everyday Arabic language, and they do not necessarily have a religious connotation. Although they originate from religious Islamic culture, they could be used by both religious and not religious individuals. In the statements of four adolescents, we noticed that when using these expressions, they did not emphasize an exclusive reliance on God nor did they mention them along with engagement in religious activities (i.e., prayer, recital of Holy Scriptures). Rather, they seemed to convey hope that things will be better in the future as illustrated by the following statements by different boys (15) "inshallah I will have money," "I don't know, I ask God that the nationality [German citizenship] comes quickly," or "[my dad] tells me by God's will, we will bring [the mother] in 1 or 2 months and I say by God's will in less than 1 months."

\section{Discussion}

Our study investigated the challenges for Syrian and Iraqi refugee youth in Germany and their main coping resources. We prioritized youths' own perspectives (Ryu \& Tuvilla, 2018) and used semi-structured interviews and thematic analysis, informed by similar studies with refugee youth in Australia (Brough et al., 2003; Gifford et al., 2009) and immigrant youth in Malaysia (Arbabi et al., 2016). We organized participants' accounts of their challenges into three levels (individual level, immediate social level, and broader societal level) drawing on Ecological Systems Theory (Bronfenbrenner \& Morris, 1998). We inductively grouped coping responses into two main categories: rely on self and rely on social support. Next, we discuss our main findings from the challenges and coping analyses.

\section{Challenges for Refugee Youth in Germany}

On the individual level, refugee youth's mental health challenges were at center stage. Adolescents discussed experiencing stress due to starting a new life in Germany, homesickness, alongside challenges with family separation and making new friends. When referring to their feelings, youth often used words such as "sad," "bad," or "not good." Only one girl mentioned experiencing depression and attending psychotherapy. A 
review on the mental health of Syrian adults affected by armed conflict (Hassan et al., 2015) found that they tended to use vague and colloquial terms to describe psychological symptoms and placed a stronger emphasis on psychosomatic symptoms. Participants in our study did not mention mental health challenges relating to war exposure or difficult flight experiences. It should be noted that the interview centered on youth's life in Germany and did not explicitly probe their war or flight experiences. Given that we did not conduct a clinical interview, we could not determine whether youth had in fact experienced traumatic events and/or suffered from mental health disorders. Moreover, the interview was conducted by an unfamiliar adult and adolescents may not have wanted to share some of their experiences in this context.

On the individual level, youth also mentioned financial strains, in line with previous reviews (Alami, 2020; Fazel et al., 2012). Adolescents witnessed their parents' financial difficulties who, for example, had to send money to family back home. Adolescents also compared their living standards to those of their peers and were aware of differences in financial resources. Such social comparisons are particularly salient for adolescents given the significance of peers and peer influence in this developmental period (Zarrett \& Eccles, 2006).

On the immediate social level, and in line with previous findings from refugee youth in Australia (Gifford et al., 2009), school and education were highly significant topics for refugee youth. Learning German occupied a central place for youth as it affected not only their placement in school classes, relationship with teachers, and academic performance, but also had potential downstream effects on further educational (e.g., continuing into higher education) and vocational opportunities. A German study on access to higher education highlighted that education is perceived by refugee students not only as a means out of poverty and marginalization in their new country, but also as a means to support their families both in the new country and their home country (Gruttner et al., 2018). The study's authors assert the need for professional counseling and high-quality language courses to support refugee youth on their way to higher education or professional apprenticeship programs.

Adolescence is a period in which meaningful bonds with friends and autonomy from family become increasingly important (Greenfield et al., 2003; Lerner \& Galambos, 1998; Zarrett \& Eccles, 2006). Our participants struggled with making new friends and they attributed this to differences in age, language and culture. Similar results were reported by a study with refugee adolescent girls in Sweden (Bergnehr et al., 2020) and refugee youth in Australia. (Riggs \& Due, 2010). They also struggled with maintaining friendships back home owing to political differences amongst 
friends, geographical distance, slim chances of reunion, and different living conditions. Concerns regarding friendships were more frequently reported in our sample than challenges with immediate family, which highlights the importance of friends for adolescents in our study. It should be noted, however, that the majority of youth in our study lived with both parents and that those who were separated from immediate family members experienced this separation as stressful. Participants' living conditions, accommodation, was also reported as stressful and dissatisfactory due to a lack of a quiet space to study, and a private place to be on their own. Similar challenges with accommodation centers were reported in a survey study of Arabic speaking refugees in Germany (Georgiadou et al., 2017).

On the broader societal level, participants reported experiencing discriminatory interactions, in the form of verbal and physical abuse, which they attributed to their looks or refugee status. Exposure to discrimination has been documented as a common and taxing experience that negatively impacts refugee youth adaptation (Australia; Buchanan et al., 2018). Additionally, refugees living in shared accommodation reported experiencing more discrimination than those living in private accommodation (Brücker et al., 2016; Gurer, 2019). A large survey study in Germany found that around a third of those surveyed favored immediate deportation of unaccompanied refugee youth and less than a quarter thought that Germany could host more unaccompanied youth (Plener et al., 2017). Germany is not yet considered a multicultural society based on diversity and policy indexes (Hanke et al., 2017), and a preference towards cultural homogeneity and a perception of foreigners as threat, rather than an enrichment, could explain negative attitudes in parts of the population. Importantly, at the same time a striking rise of volunteer movements has been recorded across different age groups, municipalities, cities, and towns in Germany. Volunteers and "welcome initiatives" not only filled the gap in providing services for asylum seekers but also created safe spaces for them in their neighborhoods and countered right-wing movements (Hamann \& Karakayali, 2016).

Youth in our study also mentioned challenges with regards to their legal status and, in particular, referred to the uncertainty of obtaining a residency permit. In Germany, the country of origin of an asylum seeker affects the time it takes to process the asylum application and may lead to different pathways for obtaining residency permits. Syrians have a much higher chance of getting asylum status than Iraqis (Pro Asyl, 2019). Within our sample, two Iraqi participants had their asylum application rejected and were in the process of appealing that decision, which took a toll on their overall wellbeing. This is in line with recent findings showing a relationship between legal status and mental health of asylum seeking children and adolescents in Germany (Müller, Büter, et al., 2019; Müller, Gossmann, et al., 2019). 
Taken together, our findings provide valuable insights into refugee adolescents' lives in a high-income country such as Germany. First, these challenges mirror two interrelated aspects of refugee youth's experiences, namely their experiences as refugees (e.g., losing contact with significant social networks at home, learning a new language) and their experiences as adolescents (e.g., importance of friendships). There is a lack of empirical studies examining refugee youth development in the context of cultural transition although the significance of such integration has been highlighted in recent review articles (Juang et al., 2018; Lustig, 2010; Ward \& Szabó, 2019). Second, education was a frequently reported challenge by adolescents in our study and one with a large impact on the future aspirations of refugee youth in their new countries. Educational challenges, combined with low income, inadequate living conditions, uncertainty about their legal status, and an exposure to discrimination all affected the quality of life and wellbeing of young refugees. Future work could investigate how these challenges develop over time and whether they are resolved after a prolonged stay in Germany.

\section{Coping Responses by Refugee Youth}

In our analysis of participants' coping statements, we grouped their strategies as "rely on self" and "rely on others" as we were primarily interested in who they relied on for support (see also the wording of our question "who helped you with this challenge?"). Our participants accessed both social networks and inner resources (avoidance, persistence, activity seeking, active engagement) to deal with the different challenges they faced, with the exception of economic challenges as family support was the only coping resource mentioned there.

Examining cultural variation in coping preferences is important to understanding coping in context (Ward \& Szabó, 2019), and, to our knowledge, there are no previous studies on coping by refugee youth from the Eastern Mediterranean region in a high income country like Germany. There are parallels between our findings and those of Muller, Brewer, et al. (2019) who found that migrant adolescents in the US used emotion focused coping strategies and problem focused coping strategies. In our sample, emotion-based strategies included avoidance of and seeking distractions from a challenging situation or accessing social support as a source of comfort. Our participants also showed problem focused coping by actively attempting to resolve their challenges or by accessing social support to access relevant information and to better understand a problem.

Previous findings on refugee youth wellbeing emphasized the role of religion as a protective factor and a coping resource (Alami, 2020; Fazel et al., 2012). In our study, some participants mentioned God in a vague colloquial term "inshallah" which translates to "God's willing" but did not report 
resorting to religious practices for dealing with the challenges in their new lives. A recent survey in 10 Arabic speaking countries found a decrease in youth's religiosity (Arab Barometer, 2019), which might explain our findings. Similar decline in interest in and practice of religion was also found in German youth, although Muslim youth in Germany were in general more religious than catholic or protestant youth (Albert et al., 2019).

Our participants referred to online resources such as Google and YouTube for help with their studies. In addition, they reported using their phones for distraction or for keeping themselves occupied. These accounts reflect a common characteristic of their generation which has a constant online presence through platforms such as YouTube, Instagram and Snapchat amongst others (Parker \& Igielnik, 2020). Recent studies showed that Syrian refugee youth in Canada used social media for community support (Veronis et al., 2018) and that refugee youth used the internet as a resource for education during their flight journey (Lucić \& Liharska, 2019).

\section{Study Limitations and Future Directions}

Our results apply to the specific context of Syrian and Iraqi refugee youth living in a high-income country and our findings may not generalize beyond the characteristics of our study sample and the context of our study. Our sample of 20 adolescents could be considered relatively small. Past qualitative research with refugee youth and adults has reported sample sizes ranging from 24 to 67 participants (Baolian Qin, 2009; Gurer, 2019; Muller, Brewer, et al., 2019). However, it is important to highlight that many of these studies included a wide range of countries of origin (e.g., Brough et al., 2003; Gurer, 2019; Muller et al., 2019), whereas our sample consisted of adolescents from "only" two countries of origin. Moreover, we had initially planned to focus on participants from Berlin but experienced difficulties in recruiting sufficient numbers of participants and consequently expanded our recruiting efforts to the neighboring city of Potsdam. It is worth mentioning that Berlin, the capital of Germany, is larger and more culturally and ethnically diverse than Potsdam. The two cities could therefore provide different experiences for newcomer refugee youth. Furthermore, it is unclear how the experiences of refugee youth in our study would relate to experiences of those settling in other parts of Germany (e.g., more rural parts). Future research could investigate the impact of location of residence in more detail.

Our interviews varied in length between participants and, although all participants answered all of the interview questions, some of them went into more detail than others. It is possible that participants' young age and unfamiliarity with a one-to-one interview setting might have had an effect on the interview length. A longer, more in-depth interview might have provided 
more nuanced insights into youth's experiences but may have necessitated a smaller sample size due to added transcription and coding workload. Generally, sharing details about interview-length, though uncommon in previous studies, provides transparency about the method and can inform future researchers' data collection plan and analysis method.

Our study offers a snapshot in time of refugee youth's experiences in Germany but did not follow up for a second (or third) interview. Longitudinal studies can address questions such as how post-migration challenges change over time (Chung et al., 2021) and whether said challenges correspond with main developmental tasks. For example, adolescents may perceive making friends as a main challenge, but as young adults they might be more concerned about accessing the job market. Future research could examine the role of length of stay on refugee youth's experiences and further help to inform future interventions and services supporting refugee youth.

\section{Conclusion}

Results from the current study highlight education, psychological wellbeing, friendship, accommodation and discrimination as major challenges for Syrian and Iraqi refugee youth in Germany. Refugee youth in our study demonstrated nuanced coping as they relied on social networks and themselves (including avoidance, persistence, activity seeking, active engagement) to mitigate the challenges of their new life. Overall, our study indicates that educational settings could be fruitful targets for programs aiming to support refugee youth and to improve their well-being. Schools could also serve as places to actively engage refugee and non-refugee students in programs aimed at understanding their diverse experiences and countering discriminatory behavior (e.g., Juang et al., 2020). Such programs could provide space for refugee youth to create their own narratives by emphasizing their strengths and unique experiences, challenging the deficit view of refugee youth (Ryu $\&$ Tuvilla, 2018). This could help in promoting a shift from focusing on challenges and risks towards acknowledging (refugee and non-refugee) students' capacities and strengths (Riggs \& Due, 2010).

Recent reports forecast increases in migration in the coming decades due to the climate emergency (Xu et al., 2020) and economic and political instabilities (Hodal, 2019). Migration and subsequent acculturative challenges may hence become a common experience for many youth world-wide. Results from our study may help to better understand the experience of youth migrating to high income countries such as Germany and support their adaptation and wellbeing. 


\section{Acknowledgments}

The authors would like to thank Hedi Blödorn, Nihal Zaghloul, Greta Schröder, M. R., H. S., and A. I. for their support with this study.

\section{Declaration of Conflicting Interests}

The author(s) declared no potential conflicts of interest with respect to the research, authorship, and/or publication of this article.

\section{Funding}

The author(s) disclosed receipt of the following financial support for the research, authorship, and/or publication of this article: The research was supported by a Freigeist Fellowship from VolkswagenFoundation (grant no. 89611-1) awarded to P. K.

\section{ORCID iDs}

Lina Alhaddad (iD https://orcid.org/0000-0001-5846-7664

Patricia Kanngiesser (iD https://orcid.org/0000-0003-1068-3725

\section{Supplemental Material}

Supplemental material for this article is available online.

\section{Notes}

1. "The purpose of this Regulation, adopted in 2003, is to determine which State is responsible for processing an asylum application. Normally this is the State where the asylum seeker first entered the EU" (UNHCR \& ECRE, n.d.).

2. 2017 and 2018 are the years of data collection for this study.

3. Comparing the prevalence of mental health disorders between newcomers and the general population might not be accurate. Groups of veterans and domestic violence survivors, for example, might provide a more informed comparison (Hameed et al., 2018).

4. Knowledge of the field of psychology and specific psychological terminology is not common in Syria and Iraq. Therefore, the interviewer explained that psychology is a field of science focused on the study of thoughts, feelings and behavior and that some psychologists work in counseling and therapy, while others, such as the interviewer, work in research to increase our understanding of these phenomena.

5. For example, there are multiple ways to spell the first author's name (in Arabic لينا ) in Roman letters: Lina, Lena, and Leena.

6. Most security guards working in refugee accommodation centers have a refugee or migration background themselves. 


\section{References}

Abou-Saleh, M. T., \& Christodoulou, G. N. (2016). Mental health of refugees: Global perspectives. BJPsych International, 13(4), 79-81. https://doi.org/10.1192/ S2056474000001379

Alami, R. (2020). From war to refuge: A literature review of the psychosocial impact of pre-and post-migration experience on the Syrian child refugee [Doctoral thesis]. Alliant International University.

Albert, M., Hurrelmann, K., \& Kantar, G. Q. (2019). 18. Shell Jugendstudie: Jugend 2019 Eine Generation Meldet Sich Zu Wort [18th Shell youth study: Youth 2019 A generation reports]. Julius Beltz GmbH \& Co. KG.

AMSSA. (2016). Newcomer youth: Challenges and strengths. Migration Matters. https://www.amssa.org/wp-content/uploads/2016/12/InfoSheet35_Youth. pdf

Amt für Statistik Berlin-Brandenburg. (2018). Kleine berlin-statistik. Amt für Statistik Berlin-Brandenburg. https://www.statistik-berlin-brandenburg.de/produkte/ kleinestatistik/AP_KleineStatistik_EN_2018_BE.pdf

Amt für Statistik Berlin-Brandenburg. (2019). Statistischer Bericht, Einwohnerinnen und Einwohner im Land Berlin am 30. Juni 2019. [Statistical report, residents in the state of Berlin on June 30, 2019]. Amt für Statistik Berlin-Brandenburg. https://www.statistik-berlin-brandenburg.de/publikationen/stat_berichte/2019/ SB_A01-05-00_2019h01_BE.pdf

Anderson, P. (2001). 'You don't belong here in Germany. . .': On the social situation of refugee children in Germany. Journal of Refugee Studies, 14(2), 187-199. https://doi.org/10.1093/jrs/14.2.187

APA Presidential Task Force on Immigration. (2012). Crossroads: The psychology of immigration in the new century. American Psychological Association. http:// www.apa.org/topics/immigration/report.aspx

Arab Barometer. (2019). Young Arabs are changing their beliefs and perceptions: New survey - Arab barometer. https://www.arabbarometer.org/media-news/ young-arabs-are-changing-their-beliefs-and-perceptions-new-survey/

Arbabi, K., Yeh, C. J., Mahmud, Z., \& Salleh, A. (2016). From monocultural to multicultural. Journal of Adolescent Research, 32(3), 371-402. https://doi. org/10.1177/0743558416630811

Baker, P., \& McEnery, T. (2005). A corpus-based approach to discourses of refugees and asylum seekers in UN and newspaper texts. Journal of Language \& Politics, 4(2), 197-226. https://doi.org/10.1075/jlp.4.2.04bak

Baolian Qin, D. (2009). Being “good” or being “popular": Gender and ethnic identity negotiations of Chinese immigrant adolescents. Journal of Adolescent Research, 24(1), 37-66. https://doi.org/10.1177/0743558408326912

Beigang, S., Fetz, K., Kalkum, D., \& Otto, M. (2016). Experiences of discrimination in Germany. Federal Anti-Discrimination Agency. http:/www. antidiskriminierungsstelle.de/SharedDocs/Downloads/DE/publikationen/ Umfragen/Handout_en_Umfrage_Diskriminierung_in_Dtschl_2015.pdf? blob $=$ publicationFile $\& v=3$ 
Bereich Statistik und Wahlen der Landeshauptstadt Potsdam. (2019). Bevölkerung: Einwohner mit Haupt- und Nebenwohnung seit 1992 [Population: Residents with main and secondary residence since 1992]. https://www.potsdam.de/bevoelkerung-einwohner-mit-haupt-und-nebenwohnung-seit-1992

Bergnehr, D., Aronson, O., \& Enell, S. (2020). Friends through school and family: Refugee girls' talk about friendship formation. Childhood, 27(4), 530-544. https://doi.org/10.1177/0907568220923718

Berry, J. W., Phinney, J. S., Sam, D. L., \& Vedder, P. (2006). Immigrant youth: Acculturation, identity, and adaptation. Applied Psychology, 55(3), 303-332. https://doi.org/10.1111/j.1464-0597.2006.00256.x

Braun, V., \& Clarke, V. (2006). Using thematic analysis in psychology. Qualitative Research in Psychology, 3(2), 77-101. https://doi.org/10.1191/1478088706qp0 63 oa

Braun-Lewensohn, O., \& Al-Sayed, K. (2018). Syrian adolescent refugees: How do they cope during their stay in refugee camps? Frontiers in Psychology, 9, 1258. https://doi.org/10.3389/fpsyg.2018.01258

Bronfenbrenner, U. (1977). Toward an experimental ecology of human development. American Psychologist, 32(7), 513.

Bronfenbrenner, U., \& Morris, P. A. (1998). The ecology of developmental processes. In W. Damon \& R. M. Lerner (Eds.), Handbook of child psychology: Theoretical models of human development (pp. 993-1028). John Wiley.

Bronstein, I., \& Montgomery, P. (2011). Psychological distress in refugee children: A systematic review. Clinical Child and Family Psychology Review, 14(1), 44-56.

Brough, M., Gorman, D., Ramirez, E., \& Westoby, P. (2003). Young refugees talk about well-being: A qualitative analysis of refugee youth mental health from three states. Australian Journal of Social Issues, 38(2), 193-208. https://doi. org/10.1002/j.1839-4655.2003.tb01142.x

Brücker, H., Rother, N., Schupp, J., von Gostomski, C. B., Böhm, A., Fendel, T., Friedrich, M., Giesselmann, M., Kosyakova, Y., \& Kroh, M. (2016). Forced migration, arrival in Germany, and first steps toward integration. DIW Economic Bulletin, 6(48), 541-556.

Buchanan, Z. E., Abu-Rayya, H. M., Kashima, E., Paxton, S. J., \& Sam, D. L. (2018). Perceived discrimination, language proficiencies, and adaptation: Comparisons between refugee and non-refugee immigrant youth in Australia. International Journal of Intercultural Relations, 63, 105-112. https://doi.org/10.1016/j.ijintrel.2017.10.006

Bundesamt für Migration und Flüchtlinge. (2017). Aktuelle Zahlen zu Asyl, Ausgabe: Dezember 2017 [Current figures on asylum, edition: December 2017]. https:// www.bamf.de/SharedDocs/Anlagen/DE/Statistik/AsylinZahlen/aktuelle-zahlenzu-asyl-dezember-2017.pdf?_blob=publicationFile \&v $=6$

Bundesamt für Migration und Flüchtlinge. (2018). Aktuelle Zahlen zu Asyl, Ausgabe: Juni 2018 [Current figures on asylum, edition: June 2018]. https://www.bamf. de/SharedDocs/Anlagen/DE/Statistik/AsylinZahlen/aktuelle-zahlen-zu-asyljuni-2018.pdf?_blob=publicationFile $\& v=4$ 
Chung, J. M. H., Meijer, L., Zonneveld, R., Sawaf, Z. A., Alajak, K., Moopen, N., Rahim, H., Çiftçi, L., Alisic, E., Stellar, J., Mooren, T., Sleijpen, M., Tešanovic, T., Baker, H. A., Dali, R., Papadantonaki, M., Papakosta, N., Antink, M., Charisopoulou, S., . . . Laceulle, O. (2021). Initial insights from a study of emotions and positive personality change in Syrian origin young adults who have recently resettled in the Netherlands. PsyArXiv. https://doi.org/10.31234/ osf.io/xvqrs

Crul, M., Keskiner, E., Schneider, J., Lelie, F., \& Ghaeminia, S. (2017). No lost generation: Education for refugee children a comparison between Sweden, Germany, The Netherlands and Turkey. In R. Bauböck \& M. Tripkovic (Eds.), The integration of migrants and refugees: An EUI forum on migration, citizenship and demography (pp. 62-79). Robert Schuman Centre for Advanced Studies, European University Institute.

d'Abreu, A., Castro-Olivo, S., \& Ura, S. K. (2019). Understanding the role of acculturative stress on refugee youth mental health: A systematic review and ecological approach to assessment and intervention. School Psychology International, 40(2), 107-127.

Dresing, T., Pehl, T., \& Schmieder, C. (2015). Manual (on) transcription: Transcription conventions, software guides and practical hints for qualitative researchers (3rd English Edition). Author. https://www.audiotranskription.de/ english/transcription-practicalguide

Ebata, A. T., \& Moos, R. H. (1991). Coping and adjustment in distressed and healthy adolescents. Journal of Applied Developmental Psychology, 12(1), 33-54. https:// doi.org/10.1016/0193-3973(91)90029-4

Ellis, B. H., MacDonald, H. Z., Klunk-Gillis, J., Lincoln, A., Strunin, L., \& Cabral, H. J. (2010). Discrimination and mental health among Somali refugee adolescents: The role of acculturation and gender. American Journal of Orthopsychiatry, 80(4), 564-575. https://doi.org/10.1111/j.1939-0025.2010.01061.x

Ellis, B. H., MacDonald, H. Z., Lincoln, A. K., \& Cabral, H. J. (2008). Mental health of Somali adolescent refugees: The role of trauma, stress, and perceived discrimination. Journal of Consulting and Clinical Psychology, 76(2), 184-193.

Essau, C. A., Conradt, J., \& Petermann, F. (2000a). Frequency, comorbidity, and psychosocial impairment of anxiety disorders in German adolescents. Journal of Anxiety Disorders, 14(3), 263-279. https://doi.org/10.1016/S08876185(99)00039-0

Essau, C. A., Conradt, J., \& Petermann, F. (2000b). Frequency, comorbidity, and psychosocial impairment of depressive disorders in adolescents. Journal of Adolescent Research, 15(4), 470-481. https://doi.org/10.1177/0743558400154003

Fazel, M., Reed, R. V., Panter-Brick, C., \& Stein, A. (2012). Mental health of displaced and refugee children resettled in high-income countries: Risk and protective factors. The Lancet, 379(9812), 266-282. https://doi.org/10.1016/ S0140-6736(11)60051-2

Frankenberg, E., Kupper, K., Wagner, R., \& Bongard, S. (2013). Immigrant youth in Germany psychological and sociocultural adaptation. European Psychologist, 18(3), 158-168. https://doi.org/10.1027/1016-9040/a000154 
Georgiadou, E., Morawa, E., \& Erim, Y. (2017). High manifestations of mental distress in Arabic asylum seekers accommodated in collective centers for refugees in Germany. International Journal of Environmental Research and Public Health, 14(6), 612. https://doi.org/10.3390/ijerph14060612

Gifford, S., Correa-Velez, I., \& Sampson, R. (2009). Good starts for recently arrived youth with refugee backgrounds: Promoting wellbeing in the first three years of settlement in Melbourne, Australia. La Trobe Refugee Research Centre.

Goodman, J. H. (2004). Coping with trauma and hardship among unaccompanied refugee youths from Sudan. Qualitative Health Research, 14(9), 1177-1196. https:// doi.org/10.1177/1049732304265923

Green, King, E., \& Fischer, F. (2019). Acculturation, social support and mental health outcomes among syrian refugees in Germany. Journal of Refugee Studies. https:// doi.org/10.1093/jrs/fez095

Green, Willis, K., Hughes, E., Small, R., Welch, N., Gibbs, L., \& Daly, J. (2007). Generating best evidence from qualitative research: The role of data analysis. Australian and New Zealand Journal of Public Health, 31(6), 545-550. https:// doi.org/10.1111/j.1753-6405.2007.00141.x

Greenfield, P. M., Keller, H., Fuligni, A., \& Maynard, A. (2003). Cultural pathways through universal development. Annual Review of Psychology, 54, 461-490. https://doi.org/10.1146/annurev.psych.54.101601.145221

Gruttner, M., Schroder, S., Berg, J., \& Otto, C. (2018). Refugees on their way to German higher education: A capabilities and engagements perspective on aspirations, challenges and support. Global Education Review, 5(4), 115-135.

Gurer, C. (2019). Refugee perspectives on integration in Germany. American Journal of Qualitative Research, 3(2), 52-70. https://doi.org/10.29333/ajqr/6433

Hamann, U., \& Karakayali, S. (2016). Practicing Willkommenskultur: Migration and solidarity in Germany. Intersections. East European Journal of Society and Politics, 2(4), 70-86. https://doi.org/10.17356/ieejsp.v2i4.296

Hameed, S., Sadiq, A., \& Din, A. U. (2018). The increased vulnerability of refugee population to mental health disorders. Kansas Journal of Medicine, 11(1), 20-23.

Hanke, K., van Egmond, M., Rohmann, A., \& Boehnke, K. (2017). Intercultural relations in Germany. In J. W. Berry (Ed.), Mutual Intercultural Relations (pp. 145166). Cambridge University Press. https://doi.org/10.1017/9781316875032.007

Hassan, G., Kirmayer, L. J., Mekki-Berrada, A., Quosh, C., El Chammay, R., DevilleStoetzel, J. B., Youssef, A., Jefee-Bahloul, H., Barkeel-Oteo, A., \& Coutts, A. (2015). Culture, context and the mental health and psychosocial wellbeing of Syrians: A review for mental health and psychosocial support staff working with Syrians affected by armed conflict. UNHCR.

Hassan, G., Ventevogel, P., Jefee-Bahloul, H., Barkil-Oteo, A., \& Kirmayer, L. J. (2016). Mental health and psychosocial wellbeing of Syrians affected by armed conflict. Epidemiology Psychiatry Sciences, 25(2), 129-141. https://doi. org/10.1017/S2045796016000044

Henley, J., \& Robinson, J. (2011). Mental health issues among refugee children and adolescents. Clinical Psychologist, 15(2), 51-62. https://doi.org/10.1111/j.17429552.2011.00024.x 
Hodal, K. (2019). Arab world turns its back on religion - and its ire on the US. The Guardian. https://www.theguardian.com/global-development/2019/jun/24/arabworld-turns-its-back-on-religion-and-its-ire-on-the-us

Juang, L. P., Schachner, M. K., Pevec, S., \& Moffitt, U. (2020). The identity project intervention in Germany: Creating a climate for reflection, connection, and adolescent identity development. New Directions for Child and Adolescent Development, 2020(173), 65-82. https://doi.org/10.1002/cad.20379

Juang, L. P., Simpson, J. A., Lee, R. M., Rothman, A. J., Titzmann, P. F., Schachner, M. K., Korn, L., Heinemeier, D., \& Betsch, C. (2018). Using attachment and relational perspectives to understand adaptation and resilience among immigrant and refugee youth. American Psychologist, 73(6), 797-811. https://doi.org/10.1037/ amp0000286

Jugert, P., \& Titzmann, P. F. (2020). Developmental tasks and immigrant adolescent's adaptation. In D. Güngör \& D. Strohmeier (Eds.), Contextualizing immigrant and refugee resilience (pp. 33-50). Springer International Publishing. https://doi. org/10.1007/978-3-030-42303-2_3

Kagitcibasi, C. (2005). Autonomy and relatedness in cultural context: Implications for self and family. Journal of Cross-Cultural Psychology, 36(4), 403-422. https:// doi.org/10.1177/0022022105275959

Keddie, A. (2012). Pursuing justice for refugee students: Addressing issues of cultural (mis)recognition. International Journal of Inclusive Education, 16(12), 12951310. https://doi.org/10.1080/13603116.2011.560687

Khawaja, N. G., White, K. M., Schweitzer, R., \& Greenslade, J. (2008). Difficulties and coping strategies of Sudanese refugees: A qualitative approach. Transcultural Psychiatry, 45(3), 489-512. https://doi.org/10.1177/1363461508094678

Kirmayer, L. J., Narasiah, L., Munoz, M., Rashid, M., Ryder, A. G., Guzder, J., Hassan, G., Rousseau, C., \& Pottie, K., Canadian Collaboration for Immigrant, \& Refugee Health. (2011). Common mental health problems in immigrants and refugees: General approach in primary care. Canadian Medical Association Journal, 183(12), 959-967. https://doi.org/10.1503/cmaj.090292

Kuckartz, U. (2014). Qualitative text analysis: A guide to methods, practice and using software. Sage.

Lazarus, R. S., \& Folkman, S. (1984). Stress, appraisal, and coping. Springer.

Lerner, R. M., \& Galambos, N. L. (1998). Adolescent development: Challenges and opportunities for research, programs, and policies. Annual Review of Psychology, 49, 413-446. https://doi.org/10.1146/annurev.psych.49.1.413

Lucić, L., \& Liharska, L. E. (2019). "They are thirsty for internet more than water": Learning and cognitive development among young refugees undergoing migration. In Z. Yan (Ed.), Analyzing Human Behavior in Cyberspace (pp. 1-27). IGI Global. https://doi.org/10.4018/978-1-5225-7128-5.ch001

Lustig, S. L. (2010). An ecological framework for the refugee experience: What is the impact on child development? In G. W. Evans \& T. D. Wachs (Eds.), Decade of behavior (science conference). Chaos and its influence on children's development: An ecological perspective (pp. 239-251). American Psychological Association. https://doi.org/10.1037/12057-015 
Lustig, S. L., Kia-Keating, M., Knight, W. G., Geltman, P., Ellis, H., Kinzie, J. D., Keane, T., \& Saxe, G. N. (2004). Review of child and adolescent refugee mental health. Journal of the American Academy of Child \& Adolescent Psychiatry, 43(1), 24-36. https://doi.org/10.1097/00004583-200401000-00012

McMichael, C., Gifford, S. M., \& Correa-Velez, I. (2011). Negotiating family, navigating resettlement: Family connectedness amongst resettled youth with refugee backgrounds living in Melbourne, Australia. Journal of Youth Studies, 14(2), 179-195. https://doi.org/10.1080/13676261.2010.506529

Montgomery, E. (2010). Trauma and resilience in young refugees: A 9-year follow-up study. Development and Psychopathology, 22(2), 477-489.

Montgomery, E., \& Foldspang, A. (2008). Discrimination, mental problems and social adaptation in young refugees. European Journal of Public Health, 18(2), 156-161. https://doi.org/10.1093/eurpub/ckm073

Motti-Stefanidi, F., \& Masten, A. (2017). A resilience perspective on immigrant youth adaptation and development. In N. J. Cabrera \& B. Leyendecker (Eds.), Handbook on positive development of minority children and youth (pp. 1934). Springer International Publishing. https://doi.org/10.1007/978-3-31943645-6_2

Muller, H. A., Brewer, T. A., Patel, S. G., \& Desai, D. (2019). A qualitative exploration of parental separation and coping: Attachment disruptions among newcomer immigrant adolescents. Journal of Adolescent Research, 35(2), 179-200. https:// doi.org/10.1177/0743558419839227

Müller, L. R. F., Büter, K. P., Rosner, R., \& Unterhitzenberger, J. (2019). Mental health and associated stress factors in accompanied and unaccompanied refugee minors resettled in Germany: A cross-sectional study. Child and Adolescent Psychiatry and Mental Health, 13(8). https://doi.org/10.1186/ s13034-019-0268-1

Müller, L. R. F., Gossmann, K., Hartmann, F., Büter, K. P., Rosner, R., \& Unterhitzenberger, J. (2019). 1-year follow-up of the mental health and stress factors in asylum-seeking children and adolescents resettled in Germany. BMC Public Health, 19(908). https://doi.org/10.1186/s12889-019-7263-6

Nielsen, S. S., Norredam, M., Christiansen, K. L., Obel, C., Hilden, J., \& Krasnik, A. (2008). Mental health among children seeking asylum in Denmark - the effect of length of stay and number of relocations: A cross-sectional study. BMC Public Health, 8(1), 293. https://doi.org/10.1186/1471-2458-8-293

OECD. (2018). Working together for local integration of migrants and refugees in Berlin. OECD Publishing. https://doi.org/10.1787/9789264305236-en

Ostrand, N. (2015). The Syrian refugee crisis: A comparison of responses by Germany, Sweden, the United Kingdom, and the United States. Journal on MigrationandHumanSecurity,3(3),255-279.https://doi.org/10.1177/2331502 41500300301

Papadopoulos, R. K. (2001). Refugee families: Issues of systemic supervision. Journal of Family Therapy, 23(4), 405-422. https://doi.org/10.1111/14676427.00193 
Parker, K., \& Igielnik, R. (2020). On the cusp of adulthood and facing an uncertain future: What we know about Gen Z so far. Pew Research Center's Social \& Demographic Trends Project. https://www.pewsocialtrends.org/essay/on-thecusp-of-adulthood-and-facing-an-uncertain-future-what-we-know-about-genz-so-far/

Patel, S. G., Staudenmeyer, A. H., Wickham, R., Firmender, W. M., Fields, L., \& Miller, A. B. (2017). War-exposed newcomer adolescent immigrants facing daily life stressors in the United States. International Journal of Intercultural Relations, 60, 120-131. https://doi.org/10.1016/j.ijintrel.2017.03.002

Patel, S. G., Tabb, K. M., Strambler, M. J., \& Eltareb, F. (2014). Newcomer Immigrant Adolescents and Ambiguous Discrimination. Journal of Adolescent Research, 30(1), 7-30. https://doi.org/10.1177/0743558414546717

Petersen, A. C. (1988). Adolescent development. Annual Review of Psychology, 39(1), 583-607.

Plener, P. L., Groschwitz, R. C., Brähler, E., Sukale, T., \& Fegert, J. M. (2017). Unaccompanied refugee minors in Germany: Attitudes of the general population towards a vulnerable group. European Child \& Adolescent Psychiatry, 26, 733-742. https://doi.org/10.1007/s00787-017-0943-9

Pope, C., Ziebland, S., \& Mays, N. (2000). Qualitative research in health care. Analysing qualitative data. BMJ (Clinical Research Ed.), 320(7227), 114-116. https://doi.org/10.1136/bmj.320.7227.114

Pro Asyl. (2019). Ene, mene, muh und raus bist du! Mehr Asylsuchende von Integrationschancen ausgeschlossen [Ene, mene, muh and you're out! More asylum seekers excluded from integration opportunities]. https://www.proasyl. de/news/ene-mene-muh-und-raus-bist-du-mehr-asylsuchende-von-integrationschancen-ausgeschlossen/

Riggs, D. W., \& Due, C. (2010). Friendship, exclusion and power: A study of two south Australian Schools with new arrivals programs. Australasian Journal of Early Childhood, 35(4), 73-80. doi.org/10.1177/183693911003500409

Ryu, M., \& Tuvilla, M. R. S. (2018). Resettled refugee youths' stories of migration, schooling, and Future: Challenging dominant narratives about refugees. The Urban Review, 50(4), 539-558. https://doi.org/10.1007/s11256-0180455-z

Schachner, M. K., Juang, L., Moffitt, U., \& van de Vijver, F. J. R. (2018). Schools as acculturative and developmental contexts for youth of immigrant and refugee background. European Psychologist, 23(1), 44-56. https://doi.org/10.1027/10169040/a000312

Shakya, Y. B., Guruge, S., Hynie, M., Akbari, A., Malik, M., Htoo, S., Khogali, A., Mona, S. A., Murtaza, R., \& Alley, S. (2012). Aspirations for higher education among newcomer refugee youth in Toronto: Expectations, challenges, and strategies. Refuge: Canada's Journal on Refugees, 27(2), 65-78. https://doi. org/10.25071/1920-7336.34723

Shakya, Y. B., Khanlou, N., \& Gonsalves, T. (2010). Determinants of mental health for newcomer youth: Policy and service implications. Canadian Issues, Summer, 98-102. 
Sirin, S. R., \& Rogers-Sirin, L. (2015). The educational and mental health needs of Syrian refugee children. Migration Policy Institute.

Suárez-Orozco, C., Motti, F., Marks, A., \& Katsiaficas, D. (2018). An integrative risk and resilience model for understanding the adaptation of immigrant-origin children and youth. American Psychologist, 73, 781-796. https://doi.org/10.1037/ amp0000265

Tam, S. Y., Houlihan, S., \& Melendez-Torres, G. J. (2017). A systematic review of longitudinal risk and protective factors and correlates for posttraumatic stress and its natural history in forcibly displaced children. Trauma, Violence, \& Abuse, 18(4), 377-395. https://doi.org/10.1177/1524838015622437

Titzmann, P. F., \& Lee, R. M. (2018). Adaptation of young immigrants: A developmental perspective on acculturation research. European Psychologist, 23, 72-82. https://doi.org/10.1027/1016-9040/a000313

UNHCR. (2017). Turn the tide: Refugee education in crisis. https://www.unhcr. org/5b852f8e4.pdf

UNHCR. (2018). UNHCR global trends forced displacement in 2017. https://www. unhcr.org/statistics/unhcrstats/5b27be547/unhcr-global-trends-2017.html

UNHCR. (2020). UNHCR Global Trends 2019. https:/www.unher.org/statistics/ unhcrstats/5ee200e37/unhcr-global-trends-2019.html

UNHCR \& ECRE. (n.d.). The Dublin regulation. https://www.unhcr.org/4a9d13d59. pdf

Veronis, L., Tabler, Z., \& Ahmed, R. (2018). Project MUSE - Syrian refugee youth use social Media: Building transcultural spaces and connections for resettlement in Ottawa, Canada. Canadian Ethnic Studies Journal, 50(2), 79-100. https://doi. org/10.1353/ces.2018.0016

Ward, C. (2001). The A, B, Cs of acculturation. In D. Matsumoto (Ed.), The handbook of culture and psychology (pp. 411-446). Oxford University Press.

Ward, C., \& Szabó, Á. (2019). Affect, behavior, cognition and development: Adding to the Alphabet of acculturation (pp. 640-692). Oxford University Press.

Xu, C., Kohler, T. A., Lenton, T. M., Svenning, J.-C., \& Scheffer, M. (2020). Future of the human climate niche. Proceedings of the National Academy of Sciences of the United States of America, 117(21), 11350-11355. https://doi.org/10.1073/ pnas. 1910114117

Zarrett, N., \& Eccles, J. (2006). The passage to adulthood: Challenges of late adolescence. New Directions for Youth Development, 2006(111), 13-28. https://doi. org/10.1002/yd.179

\section{Author Biographies}

Lina Alhaddad is a doctoral student in the Faculty of Education and Psychology at Freie Universität Berlin. She received her bachelor's degree from Damascus University and a Master's degree from Kyoto University. She worked as a psychosocial counselor with refugees in Berlin. She currently investigates the mental health, acculturation, and prosociality of Arabic speaking refugee youth in Germany. 
Robin Goodwin is Professor of Psychology at the University of Warwick, where he was previously Head of Department. His research focuses on psychological adjustment to rapid change and he has studied migration amongst different populations across the globe.

Patricia Kanngiesser is an Associate Professor in Psychology at the University of Plymouth, UK. Previously, she led a research group on Cross-cultural Developmental Psychology at Freie Universität Berlin. Her research focuses on social norms, cultural learning, cooperation, and ethical behaviors and she frequently works with diverse populations world-wide. 